\title{
Uso de indicadores indigestíveis obtidos in situ e in vivo para determinar a digestibilidade de nutrientes em equinos
}

\author{
[The use of indigestible markers obtained in situ and in vivo to determine \\ digestibility of nutrients in equine] \\ K. Oliveira ${ }^{1,6}$, C. Costa ${ }^{2}$, C.M.M. Bittar ${ }^{3}$, V.P. Santos ${ }^{4}$, J.C. Sá ${ }^{5}$, P.R. Meirelles ${ }^{2}$ \\ ${ }^{1}$ Pós-doutoranda - Unesp-Botucatu - Dracena, SP \\ ${ }^{2}$ Faculdade de Medicina Veterinária e Zootecnia - Unesp-Botucatu - Botucatu, SP \\ ${ }^{3}$ Esalq-USP - Piracicaba, SP \\ ${ }^{4}$ Aluna de pós-graduação - Esalq-USP - Piracicaba, SP \\ ${ }^{5}$ Aluna de graduação - Unesp-Botucatu - Dracena, SP \\ ${ }^{6}$ Bolsista da Capes
}

\begin{abstract}
RESUMO
Objetivou-se estudar a viabilização dos indicadores internos, celulose (CELi) e lignina (LIGi) indigestíveis, obtidos pelas técnicas in situ e in vivo, para predizer a digestibilidade de nutrientes em equinos. Foram utilizados quatro cavalos castrados, por meio de delineamento em blocos ao acaso. Os tratamentos consistiram de metodologias de avaliação de digestibilidade, como a coleta total de fezes (CT) e o uso de indicadores internos, CELi e LIGi, obtidos pelas técnicas in situ (IS) na cavidade ruminal de bovinos e in vivo (IV) nos equinos, por meio da técnica do saco de náilon móvel (TSNM), totalizando cinco tratamentos. A ingestão diária de MS foi de $2,0 \%$ do peso vivo de feno de coast-cross. A CELi-IV promoveu a melhor taxa de recuperação do indicador, igualando-se à CT, em 100,31\%, enquanto a LIGi resultou nas piores taxas, na média $76,45 \%$, para ambas as técnicas $(\mathrm{P}<0,05)$. As estimativas dos coeficientes de digestibilidade dos nutrientes foram adequadamente preditas pela CELi, obtidos IS e IV, em que os valores observados foram de 46,41, 48,16, 46,90, 47,92 e 45,51\% para MS, MO, PB, FDN e $\mathrm{EB}$, respectivamente. Concluiu-se que a CELi pode ser obtida in vivo por meio da TSNM em equinos, para predizer a digestibilidade de nutrientes.
\end{abstract}

Palavras-chave: cavalo, indicador interno, método indireto e metodologia de avaliação

\begin{abstract}
The objective of this paper was to study the use of the internal indigestible cellulose (CELi) and lignin (LIGi) markers, obtained in situ or in vivo, to predict the apparent digestibility of nutrients in horses. Four castrated horses were utilized in a randomized blocks experimental design. Treatments consisted of different digestibility determination methodologies: total feces collection (TC) and use of CELi and LIGi internal markers obtained by the in situ (IS) incubation in bovine rumen and in vivo (IV) by the mobile nylon bag technique (MNBT) with horses, resulting in five treatments. The diet consisted exclusively of coast-cross hay and the average daily dry matter intake corresponded to $2.0 \%$ of the $B W$ of the horses. The CELi-IV resulted in the best marker recuperation rate (100.31\%), being similar to the control method; while the LIGi resulted in low recuperation rates $(76.45 \%)$ for both techniques $(P<0.05)$. The nutrients' digestibility coefficients were effectively predicted by CELi, obtained in situ or in vivo, with average values of 46.41, 48.16, 46.90, 47.92 and 45.51\% for DM, organic matter, crude protein, neutral detergent fiber and crude energy, respectively. It can be concluded that CELi may be obtained in vivo by MNBT in horses to predict the nutrients' digestibility coefficients.
\end{abstract}

Keywords: horse, indirect method, internal marker and evaluation methodology

Recebido em 30 de junho de 2012

Aceito em 5 de setembro de 2013

E-mail: katia@dracena.unesp.br

Apoio financeiro: CAPES 


\section{INTRODUÇÃO}

As metodologias de avaliação de alimentos baseiam-se na mensuração ou nas estimativas da ingestão e da produção fecal, sendo adotados, na maioria das vezes, os métodos indiretos. Isso porque as avaliações de digestão in vivo são muito laboriosas $\mathrm{e}$ as in vitro apresentam limitações inerentes à técnica que impossibilitam mimetizar todas as situações ocorridas in vivo, como o nível de ingestão e a taxa de passagem (Cochran et al., 1986). Para estes casos, a estimativa da digestibilidade com indicadores internos deve ser considerada, por sanar tais dificuldades.

Muitos indicadores internos podem ser utilizados na avaliação de alimentos, porém variações na sua recuperação têm sido a principal desvantagem dessas técnicas. Entre as razões para essas diferenças, encontra-se, possivelmente, a constituição da fibra de cada volumoso, por afetar a taxa e a extensão de degradação (Berchielli et al., 2005). Entretanto, Lippke et al. (1986) consideram que a fibra indigestível pode ser usada com sucesso para predizer a digestão de alimentos, inclusive em ensaios sob condições de pastejo, desde que seja mensurada adequadamente. Nesse sentido, a celulose indigestível (CELi) aparece como um dos métodos mais estudados em equinos, entre os indicadores que constituem a parede celular, e com capacidade para predizer a digestão da matéria seca (MS) de maneira muito consistente ao que ocorre in vivo (Alvarenga et al., 1997; Oliveira et al., 1998; Oliveira et al., 2003; Stein et al., 2006).

Deve-se ressaltar que os resultados do uso da lignina como indicador interno na predição da digestibilidade em cavalos têm demonstrado sua ineficiência para essa função, devido à baixa recuperação fecal, em torno de $80 \%$ (Miraglia et al., 1999; Araújo et al., 2000; Oliveira et al., 2003). A justificativa para tal ocorrência baseiase no fato de a lignina ser parcialmente digestível (Penning e Johnson, 1983), com variação de 20 a $40 \%$ em gramíneas novas (Van Soest, 1994), tornando-a ineficaz e limitando o seu emprego como indicador. Ao se assumir a possibilidade de digestibilidade parcial da lignina, sua precisão como indicador interno pode ser melhorada pela remoção de sua fração digestível. Portanto, torna-se relevante a investigação da capacidade desta fração remanescente, denominada lignina indigestível (LIGi), em realizar as estimativas pertinentes aos indicadores indigestíveis.

No que se refere às metodologias de obtenção desses componentes indigestíveis da parede celular, presentes nos alimentos, o assunto tem sido tema de estudo em ruminantes de forma pioneira. Assim, os indicadores indigestíveis podem ser determinados pela incubação de sacos de náilon na cavidade ruminal, ou seja, in situ (Lippke et al., 1986; Huhtanen et al., 1994; Freitas et al., 2002; Ítavo et al., 2002a; Ítavo et al., 2002b; Berchielli et al., 2005), ou pela incubação in vitro em líquido ruminal (Cochran et al., 1986; Lippke et al., 1986; Krysl et al., 1988; Huhtanen et al., 1994; Freitas et al., 2002). Contudo, naqueles ensaios em equinos citados acima, a metodologia sempre empregada para obtenção da CELi é a in vitro, utilizando-se como inóculo líquido ruminal. Métodos in vitro, apesar de geralmente serem precisos, requerem técnicas e equipamentos mais complexos (Miraglia et al., 1999), além da necessidade de se manter um bovino com fístula ruminal

Devido à dificuldade de se proceder a intervenções cirúrgicas nos equinos, com a finalidade de acessar o trato gastrointestinal, metodologias têm sido desenvolvidas ou são adaptadas para sanar essas limitações. Em vista disso, considera-se que a técnica do saco de náilon móvel (TSNM) usada nesta espécie animal, principalmente, para avaliar a digestibilidade de diversos alimentos pelo trato digestivo total (Machebouef et al., 1995; Araújo et al., 1996; Araújo et al. 2001; Fombelle et al., 2004), com adaptações adequadas, possa permitir a obtenção de indicadores indigestíveis in vivo. Desta forma, a viabilização de métodos que facilitem tecnicamente a obtenção de indicadores indigestíveis é imprescindível para acelerar o processo de avaliação do valor nutritivo de alimentos na experimentação de cavalos.

Neste contexto, o presente trabalho objetivou estudar a viabilização dos indicadores internos, celulose e lignina indigestíveis, obtidos pelas técnicas in situ nos bovinos e in vivo nos equinos, por meio da TSNM, em comparação ao método da coleta total de fezes, para predizer a digestibilidade aparente de nutrientes de cavalos. 


\section{MATERIAL E MÉTODOS}

O experimento foi desenvolvido na sala de metabolismo de equinos, pertencente ao Departamento de Zootecnia da Universidade Federal de Lavras e no Laboratório de Nutrição Animal do Departamento de Zootecnia, Esalq/USP. Foram utilizados quatro cavalos castrados, sem raça definida (idade e peso corporal [PC] médios de seis anos e $330 \mathrm{~kg}$ ). O ensaio de digestão foi delineado em blocos ao acaso, pois cada cavalo foi utilizado para originar os dados referentes à coleta total de fezes e às técnicas in situ e in vivo. Assim, cada unidade experimental, constituída por um animal, foi considerada um bloco, totalizando quatro repetições. Os tratamentos consistiram de metodologias de avaliação de digestibilidade, constituídos por método direto pela coleta total de fezes (CT) e indireto pelo uso de indicadores internos, celulose (CELi) e lignina indigestíveis (LIGi), obtidos pelas técnicas in situ (IS) nos bovinos e in vivo (IV) nos equinos, por meio da TSNM, totalizando cinco tratamentos.

A quantidade de alimento fornecida aos animais foi estabelecida, segundo as recomendações do National Research Council (National..., 1989), visando atender às exigências nutricionais para a categoria. A ingestão diária de MS foi de 2,0\% do PC, composta por feno de coast-cross exclusivamente, com fornecimento de sal mineral ad libitum. As refeições foram fornecidas diariamente, às oito horas, $12 \mathrm{~h}$ e $17 \mathrm{~h}$, e as sobras foram retiradas e pesadas 15 minutos antes de cada refeição. A composição química (expressos na base da MS) do feno de coastcross utilizado apresentou 91,20\% de MS, $95,21 \%$ de matéria orgânica (MO), 2,59\% de amido, 7,47\% de proteína bruta (PB), 80,70\% fibra em detergente neutro (FDN), $42,79 \%$ de fibra em detergente ácido (FDA) e $4,35 \mathrm{Mcal} / \mathrm{kg}$ energia bruta (EB).

A pesquisa teve duração total de 32 dias, sendo divididos em duas fases experimentais: a fase I constituída por 20 dias, e a fase II por 12 dias. Durante a fase I do ensaio, destinada para determinação da digestibilidade pelo método direto por meio da CT, os primeiros 15 dias foram utilizados para a adaptação dos animais às instalações, dietas e condições de manejo. Eles ficaram alojados em baias individuais, medindo $2 \times 3 \mathrm{~m}$, com piso de cimento sem cama, com comedouro para ração e sal e bebedouro tipo "balde". Após este período, os cavalos foram colocados em gaiolas de metabolismo, providas de baldes plásticos para água e sal mineral, comedouro frontal e coletor de fezes, no qual se procedeu à coleta total por cinco dias. As coletas de fezes foram realizadas quatro vezes ao dia (às seis horas, 12h, 18h e 24h), pesadas, homogeneizadas e amostradas em $10 \%$, sendo colocadas em sacos plásticos identificados e armazenados a uma temperatura de $-15^{\circ} \mathrm{C}$, para posteriores análises. Antes do início do experimento, foi administrado vermífugo de amplo espectro aos cavalos.

Ao final da fase $\mathrm{I}$, as amostras de fezes foram descongeladas à temperatura ambiente, homogeneizadas por tratamento, para obtenção de uma amostra composta para cada animal, das quais foram retiradas alíquotas de $10 \%$, pesadas e pré-secas em estufa de ventilação de ar forçada a $60^{\circ} \mathrm{C}$, por 72 horas. Após secagem, procedeu-se a uma nova pesagem e, em seguida, à moagem em peneira com crivo de $1 \mathrm{~mm}$. As análises bromatológicas (MS, MO e PB) do feno e das fezes foram feitas segundo a metodologia descrita em Silva (1989), e a da fibra em detergente neutro (FDN) segundo Van Soest et al. (1991), no Laboratório de Nutrição Animal da Faculdade de Medicina Veterinária e Zootecnia Unesp - Campus de Botucatu. A determinação de amido foi realizada de acordo com Macrae e Armstrong (1968), no Laboratório de Bromatologia, pertencente ao Departamento de Zootecnia da Esalq-USP. Os valores de EB do feno e das fezes foram determinados por meio de calorímetro adiabático (Parr Instruments $\mathrm{Co}$ ).

A fase II do experimento foi conduzida para mensuração das metodologias indiretas, sendo compostas por seis dias para cada uma das técnicas IS e IV. Para obtenção dos indicadores indigestíveis nos bovinos pelo método in situ, utilizaram-se sacos de náilon com dimensões de $7 \times 14 \mathrm{~cm}$ e diâmetro de $60 \mathrm{~mm}$, contendo $7 \mathrm{~g}$ de amostra moída a $1 \mathrm{~mm}$ para se manter a densidade de 10 a $20 \mathrm{mg}$ de MS de amostra por $\mathrm{cm}^{2}$ de superfície dos sacos (Nocek, 1988). Amostras do feno com seis repetições e das fezes em quadruplicata, para cada cavalo da fase anterior, foram incubadas por 144 horas, na cavidade ruminal de uma vaca Holandesa fistulada no rúmen, alimentada com feno de 
coast-cross e sal mineral, após período de adaptação de 15 dias.

A determinação dos indicadores indigestíveis in vivo nos equinos foi realizada por meio da TSNM. Esta fase do experimento foi conduzida em continuidade ao ensaio de digestibilidade por meio da coleta total de fezes, sendo utilizados os mesmos cavalos estabulados em baias de alvenaria e que consumiam feno de coast-cross, como descrito anteriormente, e, portanto, adaptados ao consumo do feno. Desta forma, foram utilizados sacos de náilon de poliéster branco, de tamanho interno de $3,5 \times 6,5 \mathrm{~cm}$, com porosidade determinada de $60 \mu \mathrm{m}$ e preparados de acordo com Araújo et al. (1996). Dentro de cada saco de náilon, foram colocados $1 \mathrm{~g}$ de amostra moída a $1 \mathrm{~mm}$, de feno de coast-cross ou de fezes, oriundas do método direto, mantendo-se a relação de 10 a $20 \mathrm{mg}$ de matéria seca de amostra por $\mathrm{cm}^{2}$ de superfície dos sacos, conforme recomendação de Nocek (1988).

A inserção dos sacos de náilon foi feita em quatro cavalos, via sonda nasogástrica, durante seis dias, de maneira alternada, ou seja, um dia de intubação e o seguinte de descanso, e assim sucessivamente, até completar 144 horas. Às 13 horas do primeiro dia de passagem da sonda nasogástrica, foram inseridos por cavalo quatro sacos contendo feno de coast-cross e 16 contendo fezes equinas (quatro de cada cavalo), num total de 20 sacos/cavalo, estando todos os sacos identificados. O número de repetições resultante para o feno e as fezes foi de 16 sacos para cada um. A coleta dos sacos de náilon nas fezes foi realizada quatro vezes ao dia, às seis horas, $12 \mathrm{~h}, 18 \mathrm{~h}$ e $24 \mathrm{~h}$, e a identificação deles foi feita em uma planilha. Imediatamente após cada coleta, congelaram-se os sacos até a próxima intubação (reintubação) em freezer a $-15^{\circ} \mathrm{C}$. Em momento apropriado, os sacos foram descongelados em temperatura ambiente e présecos ao ar em estufa a $55^{\circ} \mathrm{C}$, para, em seguida, serem novamente intubados. Portanto, os sacos de náilon recuperados nas fezes foram reintubados, via sonda nasogástrica, por duas vezes, até totalizarem, no mínimo, 144 horas de incubação, devido ao fato de o tempo médio de passagem dos sacos de náilon pelo trato digestivo nos cavalos ser de 48 horas.

Após incubações in situ ou in vivo, os sacos foram lavados em máquina de lavar ("tanquinho"), com água corrente, até a água sair limpa (40 $\mathrm{min})$, e levados à estufa com ventilação de ar forçada durante 72 horas a $60^{\circ} \mathrm{C}$. Em seguida, os sacos de náilon, contendo os resíduos de digestão do feno e das fezes, por animal e para cada metodologia, foram abertos e formaram uma amostra composta. Os resíduos de digestão foram, então, submetidos à extração pelo detergente em ácido, resultando em lignocelulose. Em seguida, a fração remanescente sofreu solubilização da celulose por meio do ácido sulfúrico a $72 \%$ (Van Soest $e t$ al., 1991), obtendo-se, assim, os indicadores CELi e LIGi.

A produção fecal (PF) e o coeficiente de digestibilidade (CD) da MS e dos nutrientes (N) foram estimados com base nas equações proposta por Church (1993):
$\mathrm{PF}$ na MS $(\mathrm{g} / \mathrm{dia})=$

$\operatorname{CDMS}(\%)=$
Indicador ingerido $(\mathrm{g} / \mathrm{d})$

Concentração do indicador nas fezes (g/g MS)

$100-\left(100 \times \frac{\% \text { Indicador no feno }}{\% \text { Indicador nas fezes }}\right)$

$\operatorname{CDN}(\%)=\quad 100-\left(100 \times \frac{\% \text { Indicador no feno }}{\% \text { Indicador nas fezes }} \times \frac{\% \text { Nutriente nas fezes }}{\% \text { Nutriente no feno }}\right)$

A taxa de recuperação (TR) dos indicadores foi determinada conforme Krysl et al. (1988) pela seguinte equação:

$$
\operatorname{TR}(\%)=\frac{\% \text { Indicador nas fezes } x \text { PFobservada }}{\text { Indicador ingerido }} \times 100
$$


A produção fecal e os coeficientes de digestibilidade dos nutrientes foram submetidos à análise de variância do Statistical Analysis System (SAS, 2000). A comparação entre médias foi realizada pelo teste Tukey, a $5 \%$ de significância.

\section{RESULTADOS E DISCUSSÃO}

A concentração dos indicadores indigestíveis presentes no feno de coast-cross apresentou variações significativas quanto à metodologia de obtenção, in situ $\mathrm{x}$ in vivo, demonstrando a necessidade de maior padronização dessas técnicas usadas na experimentação de equinos (Tab. 1). O teor de CELi-IS de 9,37\% foi inferior ao valor médio observado por Penning e Johnson (1983), de 12,69\%, para diversas forragens incubadas no rúmen, o que, novamente, evidenciou a falta de homogeneidade dos métodos de análise, que, de acordo com Berchielli et al. (2005), são os principais responsáveis por essas divergências de resultados entre pesquisas. As porcentagens da CELi e da LIGi in vivo, obtidas por meio da TSNM na própria espécie animal, apresentaram os maiores valores quando comparadas às incubações in situ na cavidade ruminal de bovinos; consequentemente, provocaram o mesmo comportamento de resposta para a variável referente ao consumo dos indicadores estudados pelos cavalos.
A característica de maior importância de um indicador ideal baseia-se em sua capacidade de resistir à digestão durante a exposição pelo trato gastrointestinal (Faichney, 1975). Desta forma, a análise da taxa de recuperação fecal dos indicadores demonstrou ocorrer digestão nula para CELi-IV, obtida com o uso da TSNM, por ter promovido a melhor recuperação fecal, igualando-se ao grupo controle (CT) em $100,31 \%$. Essa relativa indigestibilidade da CELIV, para cavalos que consumiram feno de coastcross, confere a este indicador grande capacidade em predizer acuradamente a digestibilidade.

Diferentemente, a LIGi resultou nas piores taxas de recuperação, na média 76,45\%, para ambas as técnicas (Tab. 1), denotando significante desaparecimento deste indicador durante o trânsito gastrointestinal. Essa incompleta recuperação da lignina tem sido verificada na experimentação animal, em razão não só da digestão aparente, mas também da ausência de estrutura quimicamente definida (Muntifering, 1982). O uso da LIGi no atual ensaio não sanou as limitações deste componente para cavalos que consumiram feno de coast-cross, pois, além de sua baixa recuperação, inferior a $80 \%$, ainda se apresentou ineficaz em melhorar o desempenho deste parâmetro em relação ao emprego da lignina sem incubação prévia (LIG). Araújo et al. (2000), ao trabalharem com equinos alimentados com feno de coast-cross, encontraram taxa de recuperação da LIG de 81,36\%, apesar de o teor dela no feno ter sido superior a $5 \%$ na MS.

Tabela 1. Concentração (\% na MS), consumo (g/d) e taxa de recuperação (\%) da celulose (CELi) e lignina indigestíveis (LIGi), em diferentes metodologias, no feno de coast-cross

\begin{tabular}{|c|c|c|c|c|c|c|}
\hline \multirow{3}{*}{ Variável } & \multicolumn{5}{|c|}{ Metodologia } & \multirow{3}{*}{$\mathrm{CV}(\%)$} \\
\hline & \multirow{2}{*}{$\begin{array}{c}\mathrm{CT}^{1} \\
T C \\
\end{array}$} & \multicolumn{2}{|c|}{ In situ } & \multicolumn{2}{|c|}{ In vivo } & \\
\hline & & CELi & LIGi & CELi & LIGi & \\
\hline Concentração & - & $9,37 \mathrm{c}$ & $5,18 \mathrm{a}$ & $12,78 \mathrm{~d}$ & $6,67 b$ & 0,30 \\
\hline Consumo & - & $51,37 \mathrm{c}$ & $28,40 \mathrm{a}$ & $70,07 d$ & $36,57 b$ & 0,10 \\
\hline Taxa recuperação & $100 \mathrm{a}$ & $89,81 b$ & $76,56 \mathrm{c}$ & $100,13 a$ & $76,35 \mathrm{c}$ & 5,00 \\
\hline
\end{tabular}

As estimativas de produção fecal, apresentadas na Tab. 2, foram adequadamente preditas pela CELi, independentemente da técnica de obtenção utilizada, resultando em média de $3,06 \mathrm{~kg}$ de fezes na MS. Ainda, CELi-IV foi a metodologia que permitiu maior aproximação entre os valores de produção fecal estimados e observados (CT) de 2,93 e 2,94kg na MS, 0,91 e 0,92\% PC e 38,69 e $38,80 \mathrm{~g} / \mathrm{kg} \mathrm{PM}$, respectivamente. Entretanto, a LIGi apresentou-se insatisfatória por superestimar este parâmetro, expresso em kg, $\%$ PC e g/kg PM, diferindo da metodologia de coleta total, em cavalos alimentados exclusivamente com feno de coast-cross. 
Tabela 2. Valores observados e estimados da produção fecal, expressos em $\mathrm{kg}$ (MS), \% do peso corporal (PC) e $\mathrm{g} / \mathrm{kg}$ de peso metabólico (PM), de equinos alimentados com feno de coast-cross em diferentes metodologias

\begin{tabular}{|c|c|c|c|c|c|c|}
\hline \multirow{3}{*}{ Produção fecal } & \multicolumn{5}{|c|}{ Metodologia } & \multirow{3}{*}{$\mathrm{CV}(\%)$} \\
\hline & \multirow{2}{*}{$\mathrm{CT}^{1}$} & \multicolumn{2}{|c|}{ In situ } & \multicolumn{2}{|c|}{ In vivo } & \\
\hline & & $\mathrm{CELi}^{2}$ & $\mathrm{LIGi}^{3}$ & CELi & LIGi & \\
\hline $\mathrm{Kg}$ & $2,94 \mathrm{a}$ & $3,28 \mathrm{a}$ & $3,86 \mathrm{~b}$ & $2,93 \mathrm{a}$ & $3,85 b$ & 5,06 \\
\hline$\% \mathrm{PC}$ & $0,92 \mathrm{a}$ & $1,02 \mathrm{a}$ & $1,21 b$ & $0,91 \mathrm{a}$ & $1,20 \mathrm{~b}$ & 5,60 \\
\hline $\mathrm{g} / \mathrm{kg}$ PM & $38,80 \mathrm{a}$ & $43,27 \mathrm{a}$ & $51,17 \mathrm{~b}$ & $38,69 \mathrm{a}$ & $50,77 \mathrm{~b}$ & 5,44 \\
\hline
\end{tabular}

${ }^{1} \mathrm{CT}=$ Coleta total de fezes; ${ }^{2} \mathrm{CELi}=$ celulose indigestível; ${ }^{3} \mathrm{LIGi}=$ lignina indigestível. Médias com letras diferentes na mesma linha diferem $(\mathrm{P}<0,05)$ entre si pelo teste de Tukey.

Os coeficientes de digestibilidade aparente do feno de coast-cross na alimentação de cavalos, obtidos com indicadores indigestíveis por meio de metodologias in situ e in vivo, estão apresentados na Tab. 3. Os CD da MS, MO, PB, FDN e EB determinados pela CT e estimados pela CELi em ambas as técnicas foram similares $(\mathrm{P}>0,05)$, porém apresentaram diferenças significativas aos resultados obtidos pelo uso da LIGi-IS e da LIGi-IV. Da mesma forma, Oliveira et al. (2003) verificaram que a CELi foi o melhor indicador para estimar os CD da MS, FDN e EB para a mesma espécie animal alimentada também com o feno de coast-cross. Contudo, os autores citados acima ainda observaram que a CELi não estimou adequadamente o CD da PB, sendo somente eficaz a sua predição em dietas contendo até $80 \%$ de feno, diferentemente do observado na atual pesquisa.
A LIGi subestimou os CD dos nutrientes estudados na alimentação de equinos, em comparação ao grupo $\mathrm{CT}$, e, portanto, não conseguiu melhorar a capacidade de predição da LIG como indicador indigestível. Desta forma, os resultados deste trabalho são concordantes aos de Araújo et al. (2000), em que expressaram a incapacidade da LIG para estimar a digestibilidade aparente do feno de coast-cross na mesma espécie animal, sendo uma limitação do indicador e não da técnica utilizada. Portanto, a TSNM em equinos para obtenção de indicadores indigestíveis é promissora na predição da produção fecal, bem como no processo de avaliação do valor nutritivo de alimentos na experimentação de cavalos.

Tabela 3. Coeficientes de digestibilidade aparente (CD) da matéria seca (MS), matéria orgânica (MO), proteína bruta (PB), fibra em detergente neutro (FDN) e energia bruta (EB) do feno de coast-cross, obtidos em diferentes metodologias na alimentação de equinos (\% na MS)

\begin{tabular}{|c|c|c|c|c|c|c|}
\hline \multirow{3}{*}{ Variável } & \multicolumn{5}{|c|}{ Metodologia } & \multirow{3}{*}{ CV (\%) } \\
\hline & \multirow[t]{2}{*}{$\mathrm{CT}^{1}$} & \multicolumn{2}{|c|}{ In situ } & \multicolumn{2}{|c|}{ In vivo } & \\
\hline & & $\mathrm{CELi}^{2}$ & $\mathrm{LIGi}^{3}$ & CELi & LIGi & \\
\hline CDMS & $46,41 \mathrm{a}$ & $40,21 \mathrm{a}$ & $29,53 b$ & $46,50 \mathrm{a}$ & $29,84 b$ & 8,10 \\
\hline CDMO & $48,16 \mathrm{a}$ & $42,18 \mathrm{a}$ & $31,83 b$ & $48,25 a$ & $32,13 b$ & 7,45 \\
\hline CDPB & $46,90 \mathrm{a}$ & $40,86 a$ & $30,26 b$ & $46,97 a$ & $30,47 b$ & 7,79 \\
\hline CDFDN & $47,92 \mathrm{a}$ & $41,87 \mathrm{a}$ & $31,52 b$ & $48,01 \mathrm{a}$ & $31,81 b$ & 7,57 \\
\hline CDEB & $45,51 \mathrm{a}$ & $49,83 a$ & $43,71 a$ & $45,60 \mathrm{a}$ & $28,66 b$ & 12,31 \\
\hline
\end{tabular}

${ }^{1} \mathrm{CT}=$ Coleta total de fezes $;{ }^{2} \mathrm{CELi}=$ celulose indigestível $;{ }^{3} \mathrm{LIGi}=$ lignina indigestível. Médias com letras diferentes na mesma linha diferem $(\mathrm{P}<0,05)$ entre si pelo teste de Tukey.

\section{CONCLUSÕES}

A celulose indigestível apresentou-se como melhor indicador para estimar os coeficientes de digestibilidade dos nutrientes em equinos. Além disso, ela pode ser obtida in vivo por meio da técnica do saco de náilon móvel em equinos, tornando-se uma técnica promissora na avaliação de alimentos. 


\section{REFERÊNCIAS}

ALVARENGA, R.C.; LEÃO, M.I.; VALADARES FILHO, S.C. et al. Fluxo de matéria seca ileal e metodologias de coletas para amostragem da digesta em equinos fistulados. Rev. Bras. Zootec., v.26, p.726-735, 1997.

ARAÚJO, K.V.; LIMA, J.A.F.; FIALHO, E.T. et al. Comparação da técnica do saco de náilon móvel com o método de coleta total para determinar a digestibilidade dos nutrientes de alimentos volumosos em equinos. Rev. Bras. Zootec., v.29, p.752-761, 2000.

ARAÚJO, K.V.; LIMA, J.A.F.; FIALHO, E.T. et al. Comparação da técnica do saco de náilon móvel com o método de coleta total para determinar a digestibilidade dos nutrientes de alimentos concentrados em equinos. Cienc. Agrotec., v.25, p.375-384, 2001.

ARAÚJO, K.V.; LIMA, J.A.F.; TEIXEIRA, J.C. et al. Uso da técnica do saco de náilon móvel na determinação da digestibilidade aparente em equinos. Rev. Soc. Bras. Zootec., v.25, p.957963, 1996.

BERCHIELLI, T.T.; OLIVEIRA, S.G.; CARRILHO, E.N.V.M. et al. Comparação de marcadores para estimativas de produção fecal e de fluxo de digesta em bovinos. Rev. Bras. Zootec., v.34, p.987-996, 2005.

CHURCH, D.C. The ruminant animal Digestive physiology and nutrition. Prentice Hall: Englewood Cliffs, 1993 564p.

COCHRAN, R.C.; ADAMS, D.C.; WALLACE, J.D. et al. Predicting digestibility of different diets with internal markers: evaluation of four potential markes. J. Anim. Sci., v.63, p.14761483, 1986.

FAICHNEY, G.J. The use of markers to partition digestion within the gastrointestinal tract of ruminants. In: MACDONALD, I.W. and WARNER, A.C.I. (Ed) Digestion and metabolism in the ruminant. Armidale, NSW, Austrália: Univ. of New England Publishing Unit 1975. pp 277-291.

FOMBELLE, A.; VEIGA, L.; DROGOUL, C. et al. Effect on diet composition and feeding pattern on prececel digestibility of starches from diverse botanical origins measured with teh mobile nylon bag technique in horses. J. Anim. Sci., v.82, p.3625-3634, 2004.
FREITAS, D.; BERCHIELLI, T.T.; SILVEIRA, R.N. et al. Produção fecal e fluxo duodenal da matéria seca e matéria orgânica estimados por meio de indicadores. Rev. Bras. Zootec., v.31, p.1525-1530, 2002.

HUHTANEN, P.; KAUSTELL, K.; JAAKKOLA, S. The use of internal markers to predict total digestibility and duodenal flow of nutrients in cattle given six different diets. Anim. Feed Sci. Technol., v.48, p.211-227, 1994.

ÍTAVO, L.C.V.; VALADARES FILHO, S.C.; SILVA, F.F. et al. Consumo, degradabilidade ruminal e digestibilidade aparente de fenos de gramíneas do gênero Cynodon e rações concentradas utilizando indicadores internos. Rev. Bras. Zootec., v.31, p.1024-1032, 2002a.

ÍTAVO, L.C.V.; VALADARES FILHO, S.C.; SILVA, F.F. et al. Comparação de indicadores e metodologia de coleta para estimativa de produção fecal e fluxo de digesta em bovinos. Rev. Bras. Zootec., v.31, p.1833-1839, 2002b.

KRYSL, L.J.; GALYEAN, M.L.; ESTELL, R.E. et al. Estimating digestibility and faecal output in lambs using internal and external markers. $J$. Agricult. Sci., v.111, p.19-25, 1988.

LIPPKE, H.; ELLIS, W.C.; JACOBS, B.F. Recovery of indigestible fiber from feces of sheep and cattle on forage diets. J. Dairy Sci., v.69, p.403-412, 1986.

MACHEBOUEF, D.; MARANGI, M.; PONCET, C. et al. Study of nitrogen from different hays by the mobile nylon bag technique in horses. Annales de Zootechinie, v.44, p.219223, 1995.

MACRAE, J.C.; ARMSTRONG, D.G. Enzyme method for determination of linked glucose polymers in biological materials. J. Sci. Agricult., v.19, p.578-581, 1968.

MIRAGLIA, N.; BERGERO, D.; BASSANO, B. et al. Studies of apparent digestibility in horses and the use of internal markers. Livestock Production Sci., v.60, p.21-25, 1999.

MUNTIFERING, R.B. Evaluation of various lignin assays for determining ruminal digestion of roughages by lambs. J. Anim. Sci., v.55, p.432-438, 1982.

NATIONAL research council - NRC. Nutrient requirements of horses. 5.rev.ed. Washington: National Academy of Sciences, 1989. 100p. 
NOCEK, J. In situ and other methods to estimate ruminal protein and energy digestibility: a review. J. Dairy Sci., v.71, p.2051-2069. 1988.

OLIVEIRA, A.A.M.A.; QUEIROZ, A.C.; VALADARES FILHO, S.C. et al. Digestão total e pré-cecal dos nutrientes em potros fistulados no íleo. Rev. Bras. Zootec., v.27, p.331-337, 1998.

OLIVEIRA， C.A.A.; ALMEIDA， F.Q.; VALADARES FILHO, S.C. et al. Estimativa da digestibilidade de nutrientes em dietas para equinos, com o uso de óxido crômico e indicadores internos. Rev. Bras. Zootec., v.32, p.1681-1689, 2003.

PENNING, P.D.; JOHNSON, R.H. The use of internal markers to estimative herbage digestibility and intake. J. Agricultural Sci., v.100, p.133-138, 1983.
STATISTICAL analysis system - SAS. SAS user's: guide statistics. Cary: 2000. 211p.

STEIN, R.B.S.; TOLEDO, L.R.A.; ALMEIDA, F.Q. et al. Estimativa da digestibilidade aparente da matéria seca por meio de indicadores internos em equinos. Rev. Bras. Zootec., v.35, p.504-511, 2006.

VAN SOEST, P.J. Nutritional ecology of the ruminant. v. 1. 374pp, 1994.

VAN SOEST, P.J.; ROBERTSON, J.B.; LEWIS, B.A. Methods for dietary fiber, neutral detergent fiber, and nonstarch polysaccharides in relation to animal nutrition. J. Dairy Sci., v.74, p.35833597, 1991. 